\title{
Assessment of the Potential of the Pharmaceutical Information Environment in the Region
}

\author{
Irina V. Spichak*, Maria A. Pasechnikova, Irina V. Zhirova, Ekaterina V. Boiko, Alina O. \\ Ivashchenkova
}

Belgorod State University, 85, Pobedy St., Belgorod, 308015, Russia

Received: $11 / 05 / 2020$

Accepted: 17/07/2020

Published: 20/09/2020

\begin{abstract}
A systematic study of pharmaceutical information activities at the regional level has been conducted. A model of the pharmaceutical information environment ( $\mathrm{PhInE}$ ) has been formed, including global, modeling, and internal spheres. Its participants, target groups, relationships between them, and factors affecting pharmaceutical information have been identified. A methodological approach to rapid analysis of the region's PhInE potential has been developed and tested. Factors of the modeling and internal sphere were studied; SWOT analysis of factors affecting PhInE performed; a program for optimizing the region's PhInE was formed.
\end{abstract}

Keywords: Pharmaceutical information, Pharmaceutical care, Pharmacy information activities, Pharmaceutical information environment

\section{Introduction}

Nowadays the role of information has increased immeasurably. Information technologies are intensively used in pharmaceutical activities [1-4]. A significant amount of research is devoted to the provision of pharmaceutical information $(\mathrm{PhI})$ and informatization of the sphere of circulation of medicines [5-8]. At the same time, much attention is paid to marketing communications, advertising activities of pharmacies, information support for dispensing drugs, and software development for the implementation of various areas of pharmaceutical activity [9-12]. However, most studies are local in nature and are implemented from the perspective of a pharmaceutical organization [13-16]. But nowadays, there are no systematic approaches to assessing the potential of the pharmaceutical information sphere and its management, in particular, at the regional level. According to this, it is advisable to multi-aspect characteristics and analysis of the pharmaceutical information environment of the region, identifying its strengths and weaknesses, opportunities and threats, determining development vectors for the purpose of management, control and monitoring. Thus, the aim of the research is the study the potential of PhInE at the regional level.

\section{Material and Methods}

The empirical base of the study was made up of 300 questionnaires of a sociological survey of visitors to pharmacies in Belgorod and 122 questionnaires of pharmaceutical employees; the results of monitoring the appeal of 1000 residents of Belgorod to pharmacy organizations; 160 expert sheets for evaluating the information capacity of pharmacies; price lists of pharmaceutical companies-distributors in the Belgorod region; statistical materials; Internet resources. Methods of logical, system, structural analysis, strategic management, economic and mathematical, sociological, pharmacoeconomical have been used.

\section{Results and Discussion}

For the purpose of rapid analysis of the region's PhInE potential, a methodological approach has been developed that includes 5 stages: 1) formation of the PhInE model; 2) study of the modeling sphere factors; 3 ) study of internal sphere factors; 4) SWOT analysis of factors affecting PhInE; 5) formation of the region's PhInE optimization program. The methodological approach is tested on the example of the information environment of the Belgorod region. At the first stage, the PhInE model was developed, which includes 3 spheres of influence of various factors on pharmaceutical information (PhI): global, modeling and internal (Fig. 1).

The global sphere is formed by factors of indirect influence: the pharmaceutical market $(\mathrm{PhM})$, modern information technologies, and the educational sector. The modeling sphere is formed by 4 groups of complex regional factors of direct influence: information needs of pharmacy visitors, information potential of the regional pharmaceutical market, consulting groups of medical and pharmaceutical specialists, and the regional market of pharmaceutical information and reference systems. The internal sphere of PhInE is formed by the pharmacy information environment. The main participants target groups of $\mathrm{PhInE}$ have been established: subjects of $\mathrm{PhI}$ provision-pharmacy employees; objects-visitors of pharmacy organizations. At the second stage, as a result of a sociological study, the characteristics of the target groups of PhInE, information needs and problems of information exchange were determined. So, in particular, a pharmacy visitor represents as a woman of middle or retirement age ( $28 \%$ each), married $(57 \%)$, working $(47 \%)$, having a higher education $(54 \%)$ 


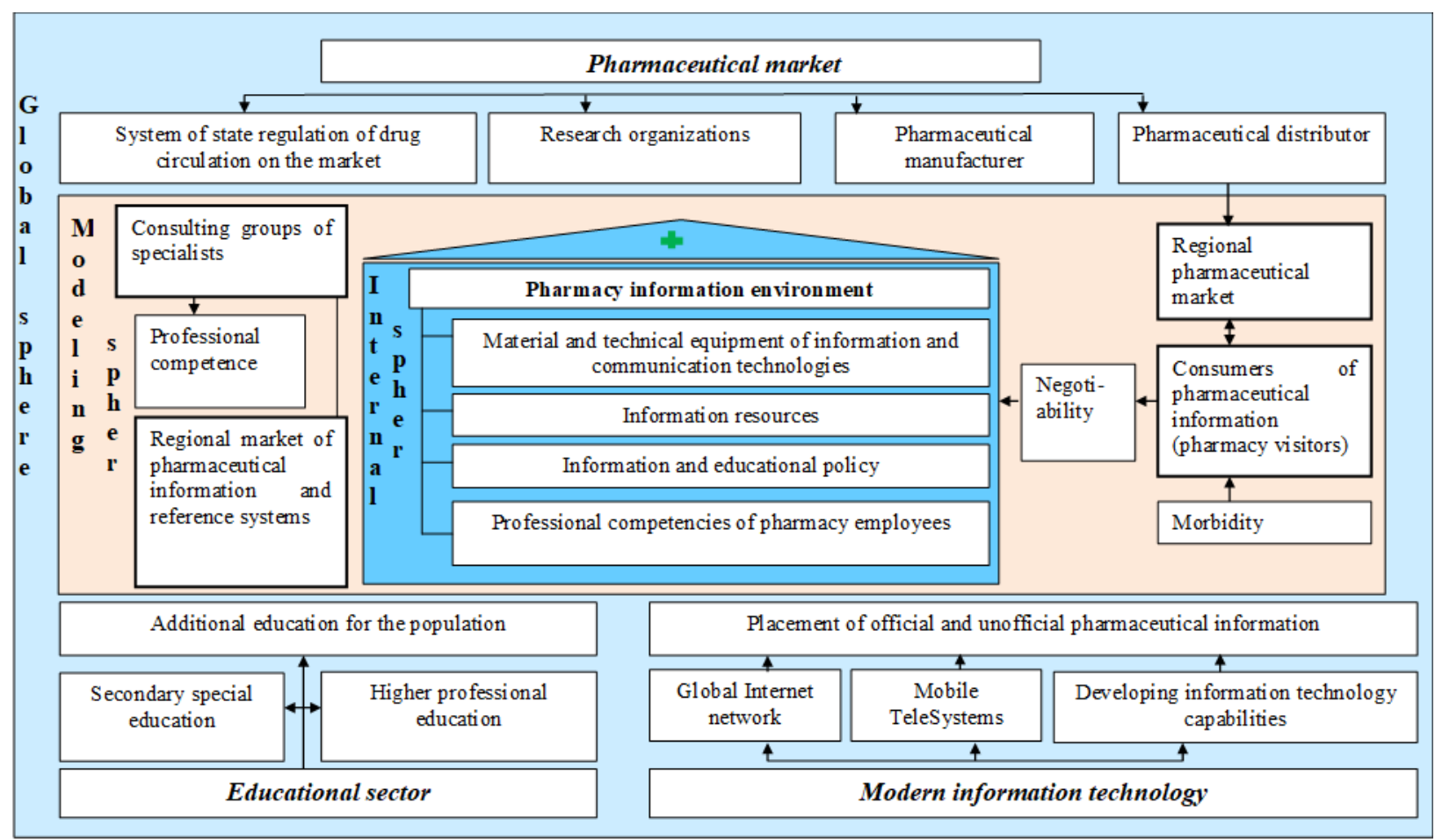

Figure 1: Model of pharmaceutical information environment

When the first symptoms of the disease appear, he/she is sent to the doctor only in $16 \%$ of cases. At the same time, he/she does not receive all the necessary amount of $\mathrm{PhI}$ at the reception, as a rule, due to lack of time with a medical specialist $(52 \%)$. The main information needs of pharmacy visitor are information about the rules for taking medications $(56 \%)$, the possibilities of their use in different age groups (33.3\%), etc. Almost $80 \%$ of respondents initially go to a pharmacy on their own decision. The main sources of information for them are friends, colleges, relatives, the Internet, and the media. They all need professional advice from a pharmacy employee (100\%).

In general, visitors trust pharmaceutical specialists $(59.7 \%)$. However, when communicating with them, they feel discomfort when identifying problems (36\%), especially in the presence of other visitors (34\%). In the course of the study, the main features of pharmacy employees who dispense medicines as subjects of providing PhI were identified. This is a woman under 30 years old with a secondary professional $(48.4 \%)$ or higher pharmaceutical education $(47.5 \%)$. The pharmacist may experience difficulties in the process of work related to the need to improve the level of knowledge in the field of new drugs $(41 \%)$. The main information needs are the data on medicines $(38.5 \%)$ and the latest changes in the sphere of state regulation of pharmaceutical activity $(32 \%)$. The main sources of information are Internet resources (85.3\%). It takes 3-4 minutes to consult users. In $21 \%$ of cases, it releases drugs depending on the social status of the pharmacy visitor. In order to evaluate pharmaceutical specialists from the position of an external observer, a sociological study of 50 heads of pharmacies in Belgorod was conducted. As a result, we studied their opinion on what qualities the "ideal" employee should have and what information needs they may have in the course of their activities. According to respondents, the determining criteria for selecting employees for a position are the presence of higher or secondary specialized pharmaceutical education (30\%), good knowledge of the range of medicines and possession of effective sales skills (20\%), work experience (15\%), ability to work with software (10\%), positive feedback from the previous job and age $(5 \%)$. Among the main qualities required in the activities of pharmacy dispensing employees, pharmacy managers note sociability (30\%), stress resistance (20\%), conscientiousness $(25 \%)$ and self-confidence and $(15 \%)$, tact (10\%), analytical abilities and energy (5\% for each). At the same time, employees, according to the opinion of pharmacy managers, should first of all be competent in the knowledge of clinical pharmacology (35\%) and pharmaceutical market offers $(30 \%)$; possess effective sales practices $(25 \%)$; know the rules for storing medicines (20\%); apply the principles of merchandising (15\%); use SOFTWARE (10\%); know the specifics of drug interaction $(5 \%)$. The portraits formed on the basis of data from a sociological survey of managers and employees of different pharmaceutical organization are similar in the most positions. However, the expectations of managers regarding the information capital of pharmacy specialists are not justified - employees constantly have lack information and/or time to get it.

At the third stage, the factors of the modeling sphere have been studied. For the purpose of accelerated assessment of the region's PhInE potential, global factors that have an indirect impact on information activities were not taken into account. The morbidity rate of the population of the Belgorod region was analyzed. It directly affects by the number of requests from the population for medical care in medical institutions, as well as for pharmaceutical care in pharmacy organizations. In connection with the appearance of the disease in a patient he/she gets a need for information on this nosological form and methods of its treatment. The main diseases that dominated in region are the diseases of the respiratory system $(31.9 \%)$, circulatory system $(8.3 \%)$, musculoskeletal system and connective tissue $(7.4 \%)$, etc. The leading nosological forms are diseases characterized by high blood pressure $(2.2 \%)$; gastritis, duodenitis, functional disorders of the stomach $(2.2 \%)$; myopia $(1.9 \%)$. Further, in order to identify the main reasons for visiting pharmacies by the population and determine information needs, we studied the appeal of 1000 residents of Belgorod to pharmacy organizations. As a result, the structure of causes of complaints has been formed, including 3 main groups: diseases of various organs and systems (53.3\%); symptoms and ailments (40.7\%); 
cosmetic, trichological and dental problems (6\%). Among the identified nosologies, diseases of the circulatory system (22.7\%), infectious and parasitic diseases $(22.1 \%)$, diseases of the digestive system $(14.8 \%)$, respiratory $(9.2 \%)$, genitourinary $(6.4 \%)$, nervous system $(5.8 \%)$ prevail. The group "symptoms and ailments" includes 28 items, including: headache (15.7\%), cold $(14.5 \%)$, runny nose and hypovitaminosis (13.3\%), cough (7.9\%), sore throat $(7.6 \%)$, shallow skin lesions $(3.7 \%)$, nervous tension $(3.4 \%)$, high blood pressure, heart pain, allergies $(2.2 \%)$, fever, muscle and joint pain $(1.7 \%)$, Diarrhea $(1.5 \%)$, etc. The main dental, cosmetic and trichological problems are: acne $(16.7 \%)$, dry skin $(13.3 \%)$, darkening of tooth enamel (11.7\%), hair loss, dandruff and wrinkles (10\%), calluses and increased sweating $(6.7 \%)$, delayed hair growth (5\%), burns, vascular asterisks and gum inflammation (3.3\%). Further, the participation of consulting groups of medical and pharmaceutical specialists in PhInE was evaluated. It has been established that in the Belgorod region all of the consulting team are present. They are an educational institution of postgraduate education, the attestation and accreditation Committee, the educational structure of the qualification, academic and professional community, medical professionals, medical representatives, marketing groups pharmaceutical manufacturers to promote the medicines at the regional pharmaceutical market, the consulting group for the analysis of the pharmaceutical market.

The regional market of information and reference systems have been also studied. Available resources include: www.apteka.ru, www.poisklekarstv.ru, www.analogilekarstv.ru, www.pharmacevtika.ru, www.analit.net, www.apteki.su, the program "Analyt: pharmacy". However, not all pharmacies in the region are connected to the available resources, and the information component is provided only with instructions for use. The information potential of the regional pharmaceutical market is also analyzed as part of the modeling sphere research. The greatest need for $\mathrm{PhI}$ arises, as a result, on drugs increased demand. In this regard, the most popular drugs have been identified. 338 TOP positions of trade names of medicinal products related to 270 active substances, 156 pharmacological and 14 ATX groups have been identified. In particular, among the ATX classes, the leading position is occupied by drugs acting on the nervous system, digestive tract and metabolism, and the respiratory system. At the third stage of rapid analysis of the region's financial system, its internal sphere, represented by the pharmacy information environment, was studied. To characterize the internal sphere, the concept of "pharmacy information capacity" (PhIC) is introduced. It is mean the maximum amount of professional information that can be provided in a pharmacy organization to consumers: the population, medical professionals, colleagues, depending on the available resources. In order to assess the internal sphere, a methodological approach to the examination and evaluation of pharmacy organizations was developed. It involves a consistent quantitative assessment of all its components: the material and technical equipment of information and communication technologies, information resources, information and educational policy of the pharmacy, and an assessment of the professional information capital of its employees. Expert sheets have been developed to define each component of the PhIC, containing criteria and a range of assessments. The experts are the heads of pharmacies. All criteria of expert lists were evaluated on a 5-point scale. Then the average value of each $\mathrm{PhIC}$ component and its total value have been determined. The methodological approach was tested on the example of 20 pharmacies in Belgorod.

As a result of the assessment of the material and technical equipment of information and communication technologies, the indicator was 3.2 points, which indicates its satisfactory condition. A low value indicates insufficient use of new technologies. Information resources for 20 pharmacies were rated at 2.5 points, which is an indicator of their poor condition: the management pays insufficient attention to the organization of information and consulting services. The average value of the information and educational policy was 3.3 points (satisfactory), which indicates the need to improve the organization of training and testing the competencies of pharmacy employees. Professional information capital of employees was 3.1 points (satisfactory). To improve the quality of information and consulting services provided, it is necessary to improve the professional knowledge of specialists. The average value of the $\mathrm{PhIC}$ is 12.1 points out of 20 possible, which in accordance with the developed scale indicates its level - "below average". We identified leaders among pharmacies, but their level was low. Thus, in the Belgorod region, the information activities of pharmacies are not sufficiently developed. At the next stage, a comprehensive analysis of the studied factors was performed using a SWOT matrix that reflects the strengths and weaknesses of PhInE, opportunities and threats to its development (Table 1). The main negative trends formed the basis of the regional program for optimizing the PhInE of the Belgorod region, which includes 6 action vectors with details of activities, responsible performers, participants, and implementation deadlines. Priority areas for improving $\mathrm{PhInE}$ include: 1) organizational support of information activities of pharmacies; 2) monitoring of information activities of pharmacy organizations; 3) improving the quality of information support for pharmacy visitors; 4) improving the human resources of pharmacy organizations in the region; 5) formation of a regional regulatory framework for providing pharmaceutical care and information and consulting services; 6) development of modern technologies for providing pharmaceutical information. Thus, in order to implement a comprehensive analysis of the existing $\mathrm{PhI}$ system, the $\mathrm{PhInE}$ model was developed. It has been established that it has a complex structure with a complex of relationships between participants and target groups. Therefore, it is advisable to conduct a systematic study and assessment of the potential of PhInE for competent regulation of all processes occurring in it.

However, there were no approaches to studying and managing information activities at the regional level. In this regard, a methodological approach has been developed to conduct a rapid analysis of the potential of PhInE in the region, which allows for rapid assessment of its state with a view to further impact on negative trends in its development. To ensure monitoring and optimization of information activity of pharmacies, the technology of information capacity examination of a pharmacy organization was developed for the first time. Quantitative expression (PhIC) also makes it possible to identify leaders and outsiders in the provision of pharmaceutical information services. 
Table 1: SWOT Analysis Matrix

\begin{tabular}{|c|c|c|}
\hline & Opportunity & Threats \\
\hline $\begin{array}{l}\checkmark \\
\checkmark\end{array}$ & $\begin{array}{l}\text { Priority addressing of the population to the } \\
\text { pharmacy for PhI; } \\
\text { The trust of patients to pharmacist; } \\
\text { Interest of patients in receiving information } \\
\text { services in pharmacies, including through } \\
\text { innovative technologies; } \\
\text { Public satisfaction with information } \\
\text { provided by pharmaceutical specialists; } \\
\text { Availability of the faculty of pharmacy of } \\
\text { NRU "BelSU" as an information and } \\
\text { educational center; } \\
\text { Active participation of consulting groups of } \\
\text { specialists of the Belgorod region in } \\
\text { information exchange. }\end{array}$ & $\begin{array}{l}\checkmark \text { Increase in the general morbidity rate of the population; } \\
\checkmark \text { High level of morbidity in the Belgorod region in comparison with other } \\
\text { subjects of the Central Chernozem economic region; } \\
\checkmark \text { Increase in the frequency and variety of reasons for visits to the pharmacy; } \\
\checkmark \text { Public visits to a pharmacy organization without a doctor's appointment; } \\
\checkmark \text { Wide range of products on the regional pharmaceutical market; } \\
\checkmark \text { Information deficit that occurs in the population, including after visiting a } \\
\checkmark \text { doctor; } \\
\checkmark \text { Unreliability of sources of information about medicines used by the } \\
\checkmark \text { population; } \\
\text { Underdevelopment of the pharmaceutical information and reference systems } \\
\text { market in the Belgorod region. }\end{array}$ \\
\hline & Strengths & Weaknesses \\
\hline & $\begin{array}{l}\text { All pharmacies are equipped with computers } \\
\text { and Internet access; } \\
\text { The availability of software for automated } \\
\text { accounting of goods flow; } \\
\text { Availability of necessary information for } \\
\text { visitors in pharmacies on signs and in sales } \\
\text { halls, advertising materials; } \\
\text { Updating pharmaceutical knowledge and } \\
\text { skills of pharmacy employees at conferences, } \\
\text { seminars, and trainings. }\end{array}$ & $\begin{array}{ll}\checkmark & \text { Low information capacity of pharmacy organizations; } \\
\checkmark & \text { Low professional information capital of pharmacy employees; } \\
\checkmark & \text { Unsatisfied information needs of pharmaceutical specialists, significant } \\
& \text { information load; } \\
\checkmark & \text { Lack of modern technologies for providing PhI in pharmacies (Internet sites, } \\
& \text { infomats, "running" information lines, etc.); } \\
\checkmark & \text { Lack of periodicals in pharmacies; } \\
\checkmark & \text { Lack of algorithms for providing pharmaceutical care, standards for providing } \\
& \text { information and consulting services in most pharmacies; } \\
\checkmark & \text { Lack of conditions for providing consulting services in pharmacies (a large } \\
& \text { flow of visitors, lack of information departments, pharmacists who carry out } \\
& \text { information and consulting work, etc.); } \\
\checkmark & \text { Lack of practice of conducting informational seminars for pharmacy visitors; } \\
\checkmark & \text { Non-interference of the employee training system inside the pharmacy; } \\
\checkmark & \text { Insufficient monitoring of pharmacy employees ' knowledge; } \\
\checkmark & \text { Lack of initiative of pharmacy specialists in providing PhI; } \\
\checkmark & \text { Lack of anonymity in the process of providing PhI to pharmacy visitors. }\end{array}$ \\
\hline
\end{tabular}

\section{Conclusion}

The effects of implementing the results of the study can be traced in several directions: by influencing pharmacy organizations, the population and the management of pharmaceutical activities in the region. The pharmacy's significance lies in the possibility of rapid system analysis and timely adjustment of its information activities and, as a result, improving the quality of information services, forming loyal visitors, and increasing competitiveness. For the population it lies in the formation of pharmaceutical literacy, correct conscious behavior and adherence to treatment, improving health and improving the quality of life. The use of the research results by regional pharmaceutical management bodies is appropriate for the formation of directions for the development of $\mathrm{PhInE}$ in the region, improving the regulatory regulation of $\mathrm{PhI}$ provision, monitoring and control of information and consulting activities of pharmacy organizations in order to improve its quality in the region.

\section{References}

1. Goundrey-Smith S. Barcodes and Logistics. InInformation Technology in Pharmacy. 2013:175-192.

2. Gubsky SM. Information technologies in the modern organization of the pharmacy business. Provizor. 2008;2:40-44.

3. Moshkova LV, Ezhova TV. Assessment of awareness of Internet sites for specialists in the field of pharmacy. Pharmacy. 2011;2:5052 .

4. Preferansky NG, Simakov OV, Preferanskaya NG, Selyanin AO,
Vitukhin VS, Pavlov AG. New opportunities for professional use of Federal information services. Health care. 2014;6:32-41.

5. Heidari K. Evidence Based Pharmaceutical Care. Journal of Pharmaceutical Care. 2014:140-1.

6. Katkova AD, Kirschina IA, Soloninina AV. Internet technologies in the organization of pharmaceutical assistance to the population. New pharmacy. 2013;5:19-21.

7. Kapustin A. Pharmacies go online. Pharmaceutical review. 2013;11(140):24-29.

8. Safiullin RS, Shakirova DH. Quality of drug care management and information and computer technologies. Pharmacy. 2011;5:29-30.

9. Baranov A. Problems with choosing an automated control system: we take into account all nuances. Russian pharmacies. 2010;7(165):20-21.

10. Gorbunov VN. Business online. Pharmacy business. 2013;9:5253.

11. Gusev AV. Criteria for choosing a medical information system (Rus.). Health Manag. 2010;5:38-45.

12. Ibragimova GYa, Gaisarov AKh. Advertising and display of medicines. New pharmacy. 2015;4:45-49.

13. Garifullina GH, Muslimova NN, Providing information services in a pharmacy. Medfarmtest Volga Region. 2012;25:5-6.

14. Ezhova TV, Moshkova LV. Methodological approaches to optimizing the behavior of pharmacies in the market of information products and services. Life without dangers. Health. Prevention. Longevity. 2011;1: 28-30.

15. Kirschina IA, Soloninina AV, Shumilovskikh EV. Optimization of the maintenance of the population with medications. New pharmacy. 2010;10: 22-27.

16. Muraveva KYu. Pharmacy on the Internet. New pharmacy 2015;4: 50-56. 